\title{
ISLAMIC BUTCHER SHOP READ AS A REFUGEE NOVEL
}

\author{
Jooyoung Kim \\ Konkuk University \\ jooyoki@konkuk.ac.kr
}

\begin{abstract}
In 1950, a civil war broke out between the North Korean army (with the support of China and the Soviet Union) and South Korea (supported by the US and UN forces). Son Hong-gyu's novel Islamic Butcher Shop (2010) begins with the background of Turkish and Greek soldiers-among the UN troops from 16 countries, including the US military. They have not returned to their home countries but remain in Korea and live with the trauma of war. Islamic Butcher Shop is a novel emphasizing images of refugees based on multicultural perspectives.

The boy, who is the central figure and narrator of this novel, is not given a name. He is not categorized as a "citizen" under the family register system of Korea, but he is stuck somewhere between being a Korean national and not having citizenship. So why did this novel have to bring refugees to the scene of Korean society in the 1980s? Korean society tends to see refugees as unfamiliar because of a single-race nationalism based on the ideology of pure blood. After South Korea joined the Refugee Convention in 1992, the number of refugee applicants increased, causing South Koreans to be more aware of the refugee issue. Koreans tend to be cautious about not only refugees but also immigrants. This is partly due to the fact that the narrative of the nation-state emphasizes homogeneity and conceals the uniqueness exhibited during modernization after the postcolonial period in Korea.

In this situation, Islamic Butcher Shop, by portraying the lives of refugees against the backdrop of the trauma of war and not of political or economic migration, serves as a wake-up call for the distorted ideology of pure blood and nationalism. That is, the novel dismantles stereotypes based on race, religion, or social class.
\end{abstract}

\section{Keywords}

Refugee, Multicultural perspectives, Son Hong-gyu, Ideology of pure blood, Mobility 


\begin{abstract}
About the Author
Jooyoung Kim is an Assistant Professor and Deputy Director at the Academy of Mobility Humanities, Konkuk University, South Korea. Her research interests are Japanese literature, diaspora, multicultural studies, and mobility humanities. She has co-authored Criticism of Korean Multiculturalism (2016), Literature, Nation, and State (2012) among others. Her recent articles include "The Identity of a Young Intellectual of Colonial Korea: Focusing on Into the Light by Sa-ryang Kim," Kritika Kultura 28 (2017), and "New Horizon for Interpretation of Multicultural Literature in Korea: Multicultural Imagination in Son Hong-gyu's Novel and $\mathrm{Ha}$ Jong-oh's Poetic Literature," Universitas - Monthly Review of Philosophy and Culture (2015). This paper was supported by Konkuk University in 2019.
\end{abstract}




\section{REFUGEES AS A MOTIF: PEOPLE WITH SCARS}

In 1950, a civil war broke out between the North Korean army (with the support of China and the Soviet Union) and South Korea (supported by the US and UN forces). Prior to July 27, 1953, when the Korean Armistice Agreement was signed, an estimate of $1,376,500$ people were killed, including civilians, and many yet unspecified number of soldiers were wounded (D. Park). Son Hong-gyu's ${ }^{1}$ novel Islamic Butcher Shop begins with the background of Turkish and Greek soldiers among the UN troops from 16 countries, including the US military. They have not returned to their home countries but remain in Korea and live with the trauma of war. Islamic Butcher Shop is a novel emphasizing images of refugees based on multicultural perspectives.

Hassan, a Turkish veteran of the Korean War, is the owner of the "Islamic Butcher Shop." He is a peculiar man who sells pork although he is Muslim. He does not sell the meat as Halal food for Muslims to eat; it is pork for ordinary Korean people. Concerning the implication of the title of the story, a critic points out, "The combination of 'Islam' and 'butcher' represents the reality in which native people and immigrants cannot get along with each other in a multicultural society, and at the same time it means creation through difference" (Lee 491). This interpretation is not utterly unfounded, but the title can be read as a strategy to amplify the curiosity of the readers in the whole story about why a Muslim man is engaged in a job deemed taboo in Islam. It brings to the fore the self-imposed punishment and the conflict of "disharmony."

That Hassan, a Muslim, sells pork at a butcher shop suggests that he is a refugee in a foreign country. Likewise, it hints that he is also imposing punishment upon himself but the novel leaves these details obscure to stimulate the reader's imagination. The text, however, offers a clue about this mysterious self-imposed punishment through a friend of Hassan named Yamos, who lives in the same multiplex housing complex, and who is a veteran from Greece who remained in Korea after the Korean War. Yamos mistakenly massacred the whole family of his uncle while he was flying a fighter jet during the Greek Civil War (1946-1949), and in despair, came to Korea to fight in their civil war because of his desire to "run farther and farther away from his hometown" (103). The Greek Civil War was an early conflict in the Cold War era, and had essentially the same characteristics as the large-scale Korean War, which was also a major military conflict in the Cold War era. The misfortune of war has led to the murderous act of Yamos mistakenly killing his relatives, which the perpetrator himself could not understand nor accept. The presence of Yamos plays an auxiliary role in indirectly giving a glimpse of Hassan's past, which is cloaked in secrecy. 
In the midst of this discord, the narrator of the novel appears. He moved around from one orphanage to another before Hassan adopted him. Hassan chooses the narrator, who is the most troublesome of the many orphans. Perhaps the only clue to explain the reason for Hassan's decision is that the narrator has terrible scars on his body. The narrator is curious about the origins of scars throughout the novel and is very self-conscious of these marks as someone with scars on his whole body. "My scars, the origin of which I do not know. I do not remember it, but then how can my body remember it?" the narrator asks himself. "I was also curious about why I am so obsessed with the scars" (111). The boy has anxiety over the absence of his origin, and his self is generally sealed off, consisting of memories of living as a citizen of a nation state in his hometown with his parents. It is later revealed that not only "Mr. Yamos has a scar as thick as a little finger on his left jaw," but also Mr. Hassan, who has "hands covered in cuts and bruises" and "an ear that is crushed and trampled down and has lost its original shape," has the same scars as the narrator.

Excited about something, Mr. Yamos waved his arm and spilled cold coffee on me.

Mrs. Anna took off my top....

"What a terrible scar! Boy, what happened?"

Pointing to the scar under my collarbone, the man asked. I shook my head.

"Somehow, it seems familiar."

The man turned around to look at Mr. Hassan. Mr. Hassan said nothing. I guessed the man would have such a scar, too. It was not until late at night that he went out. The man waved at me in the darkness. Before that, he said,

"Now I remember. I mean the scar. I didn't know, but I am familiar with that, and Hassan had a similar one." (227)

Hassan, who has gunshot wounds and lives in Korea as a refugee-like criminal who cannot return to Turkey, the narrator, and Yamos-these are all people with scars. They are living as tenants in a two-story, multiplex housing unit in a shabby and squalid hillside shanty town with alleys that branch off and connect like a maze. The boy, who is the narrator of the story, does not know where he was born or who his parents were, and he has moved around orphanages and care facilities. Now adopted by Hassan and living in a slum in Seoul, he tells the story. Based on his memory, he knows himself as a troublemaker in the care facilities and that his body carries terrible wounds from gunshots, the cause of which is unknown. Yet we could speculate based on textual clues that the narrator got these wounds during the Gwangju Democratization Movement of 1980, a protest by citizens against military oppression and ruthless suppression. The novel is set in the 1980s. Hassan stayed in Korea after he participated in the Korean War that was waged between 1950 and 1953. Considering these details, we can guess that the boy's parents might have been killed by the government forces during the Gwangju Democratization 
Movement. Although the boy survived, the gunshot wounds remain. Hassan would have probably identified with the scars imprinted on the boy's body. The plot is deeply shadowed by civil war trauma from the Korean War and the Gwangju Democratization Movement.

The boy has been exposed to the violence of the army of the state, and having lost his memory, he wanders from orphanage to orphanage with gunshot wounds. The image is not different from that of a refugee in one's own country. Strangely enough, the boy, who is the central figure and narrator of this novel, is not given a name. $\mathrm{He}$ is not categorized as a citizen under the family register system of Korea, but is stuck somewhere between being a Korean national and not having citizenship. After adopting the narrator, Hassan was so eager to send him to middle school, but he had to face frustration, which reminds us that the narrator is like a refugee who is excluded from his own nation. Hassan and Yamos, who have become refugees through war, violence, and involuntary murder, are linked with the narrator because of their shared experience of having scars.

Apart from the taciturn care of Hassan and Yamos, the boy is often looked after by Anna, the owner of the Chungnam Diner. She is also described as the "queen of scars" (26).

Now I know how Mrs. Anna would have felt. The day I first met her, the day I was stripped like a Belgian boy who does not know shame. Mr. Hassan asked Mrs. Anna to wash me.... She came along carrying a washcloth in her hand, and sighed quietly in front of my naked body. Carefully she stroked my scars-no one told me about them. $(14-5)$

While washing the scars on the narrator's body, Anna says, "There are scars on my body too" (15). Like Hassan and Yamos, she is a compassionate woman who takes care of the boy. She escaped from the violence of her husband by hiding in this neighborhood and was thus disconnected from her hometown.

Mrs. Anna tossed and turned, which made the gap between tables wider. She had a dream. It must have been a terrible dream, since she barely moved her lips, hardly able to utter a word. Soon, hot tears flowed from her bulging eyes....

"It was my childhood home. An old thatched cottage without a fence. And there were flowers blooming in the front yard, and the puppies were playing. ... The older I get, the more I miss the house. I went back to my old home in a dream. I walked along the familiar village path, past the houses of old friends, and arrived at the kitchen garden where a paulownia tree stood.... There was not a trace. It was an empty lot. (160-161) 
This dream is the only channel for Anna, who has been living as a refugee for many years, to come back to her hometown. Suffering from the trauma of killing his family, Yamos is also unable to return to his hometown. To recapitulate this section, their refugee experience has been a series of wars, murder, and violence, and they are linked by the common experience of pain, visible as scars on their bodies.

\section{THE IMAGE OF THE REFUGEE COMMUNITY}

So why did this novel have to bring refugees to the scene of Korean society in the 1980s? Korean society tends to see refugees as unfamiliar because of a singlerace nationalism based on the ideology of pure blood (Song 97). After South Korea joined the Refugee Convention in 1992, the number of refugee applicants increased, causing South Koreans to be more aware of the refugee issue. Koreans tend to be cautious about not only refugees but also immigrants. That the narrative of the nation state emphasizes homogeneity and conceals the uniqueness exhibited during modernization after the postcolonial period in Korea is partly the reason for this attitude.

However, the Korean Peninsula has been a space of mobility closely linked to refugees. Even during the period of the Joseon Dynasty, which maintained a closeddoor policy, some people came to the country as refugees and settled down to live as military officials, including some Japanese. ${ }^{2}$ Meanwhile, Jan Janse Weltevree (1595-?), a Dutchman who drifted in 1627 to Joseon, was the first naturalized European. In fact, Japan's rule of Korea in the modern era produced refugees that escaped from the Korean Peninsula to foreign countries, and their descendants settled in China, Russia, Central Asia, and Japan. The refugees who left the Korean Peninsula had no choice but to choose a means of emigration in the face of massive military conflicts such as the Sino-Japanese War (1894-5) and the Russo-Japanese War (1904-5). Some have gone into exile overseas for the independence movement, like Kim Koo, who is called the father of Korean independence. ${ }^{3}$

Nonetheless, why is there an intense resistance to accepting refugees? Since the independence of Korea from Japanese rule, South Korea has developed the primacy of anticommunism and economic development while North Korea has developed a dictatorship based on worshipping a dictator. As a result, even if refugees who have escaped North Korea settle in South Korea, South Koreans do not consider them "refugees." One reason for this is the nationalist sentiment based on the idea that they are the same people, and politically, the North Korean defectors are subject to special treatment as the 'people of the same nation.4 In other words, 
Korean nationalism is focused on "national security" (B. Lee 38-40) by underlining unity rather than acknowledging the "heterogeneity" of refugees. That is to say, the Korean Peninsula is perceived as one unified entity or one nation.

In this situation, Islamic Butcher Shop's portrayal of the lives of refugees against the backdrop of the trauma of war, and not of political or economic migration serves as a wake-up call for the distorted idea of pure blood and nationalism. In fact, this novel can be considered the best among multicultural novels written in the Korean language in that it provides an excellent description with a multicultural imagination (Kim 37-56). That is, the novel dismantles the 'stereotypes' based on race, religion, or social class. This can be confirmed, for example, in the following passage:

Anna's facial expressions during her asleep are strange. It doesn't seem strange to say that she looked like a Korean woman, or Chinese, Japanese or even Vietnamese or Indonesian. No, she even looked Hispanic, Mulato, or Sambo. In the end, it became unclear who Anna is or whose blood she inherited, and even the thought that originally a man is born as mixed race came across my mind. So do Mr. Hassan and Mr. Yamos. Despite their stubborn character, built after living in Korea for a long time, they have become woven to this place. Some immediately recognize that they are foreigners, but others could not at all. Some people claim that they are Koreans even though I let them know that they came from Turkey and Greece, respectively. (159-160)

Anna is a Korean that looks like a foreigner whereas Hassan and Yamos look like Koreans. This inverted image points to the unfriendly attitude of Korean society to those with 'mixed blood' and 'foreigners'. Some previous studies have interpreted Islamic Butcher Shop as an example of Derrida's hospitality concept or Bakhtin's cannibalism, but those studies showed no attempt to read it as a refugee story. Korean researchers are unfamiliar with refugees. Those discussions are not mistaken as methods of interpretation in the frame of multiculturalism; however, it is necessary to draw attention to the fact that they are based on the dichotomy of immigrants and the native. Here we can see why the refugees appear in the setting of the military dictatorship in Korea in the 1980s. If the perspective of a refugee is considered, one may be able to accommodate the logic of the discrimination of strangers by the native, and at the same time, avoid binary opposition. Further, one can even gain a new perspective on the criticism of the violence inherent in the nation-state itself.

If we read Islamic Butcher Shop as a novel that narrates the lives of refugees, readers face a story of a boy living in a "refugee community" who does not know even basic information about his own birth. Son Hong-gyu's literary imagination for the refugee community seeks emotional solidarity with refugees, going beyond 
the hostile attitude displayed toward political refugees from Yemen which created turmoil in Korean society in 2018. In this respect, this is also an ongoing literary task for us. The mobility of the refugee is somewhat different from the binary opposition of the home to return to and the strange place where one lives-an issue in the diaspora debate. A refugee has no place to return to.

I have no home anyway. I had no archetypal landscape to miss, nor recollection of familiar things to dream of returning to. Hence, everywhere I go is my hometown and home country. No matter who I meet, they are my old friends and family. Of course, it also means that nowhere is my home, and no one is my friend or family. (54)

The boy who recalls only memories of wandering through orphanages can be compared to the refugees who wander from one camp to another without a residence. The movement of the body of the boy accommodated in an orphanage is limited, and he can be said to be a "refugee" in the territory of a country seeking settlement because he has no parents or home. As he says, "everywhere I go is my hometown and home country," which means he does not even belong to the "community of fantasy" called "Koreans" as Benedict Anderson argues. Moreover, the origin of the boy, the main character, is unknown. This novel does not describe anything other than the people and places that make up the community, and the people who gather in this community are those that have escaped from the past both in space and time.

As mentioned earlier, there are terrible gunshot wounds left on the body of Hassan, and we do not know exactly why, but he suffers from nightmares and a kind of trauma. The novel describes this peculiar person very minimally. It must be so, because the boy who was adopted by the man is the narrator, and the story has a structure in which Hassan cannot be described unless he speaks about his life directly. We are given no information about whether Hassan has a family in Turkey or why he lives as a refugee in a foreign land far away from home. Hassan is a Muslim who can recite the entire Quran, but he does not go to a mosque. However, it is clear that Hassan is a Muslim since he practices Islamic worship at home. Such a plot is a metaphorical expression of the rejection experienced by a person on this land. That a devout Muslim runs a butcher shop is indicative of his acceptance of a refugee's suffering through this self-inflicted penalty. ${ }^{5}$

Besides the appearance of a pseudo-family (Kim 43), which consists of the narrator, Hassan, Yamos, and Anna-the "people who share scars rather than blood" (M. Lee 489) - characters in the novel are far from people who communicate normally or use standardized language. Yoo-jeong, the friend of the narrator who stutters yet can communicate with animals, is "the tough cookie" who gazes blankly at the world like a wounded animal or mumbles all day long. Also, the novel is 
full of characters who break from "standardization" and "normalization:" the old drunkard locksmith who is "bent with age, shaking hands and with a deep wrinkled face," repeating the same words all the time, the parents of Yoo-jeong who sell briquettes, and Mr. Kim, the rice seller who is a walking slang dictionary. To sum up this section, they do not use a language that communicates with power; they are speakers of pidgin within a territory that disrupts even communication with ordinary people. Here, this novel shows linguistic hybridity to represent the images of refugee communities in Korea.

\section{THE POSSIBILITY OF SOLIDARITY BETWEEN REFUGEES}

The Islamic Butcher Shop is a place where standardized language does not work, and clearly shows the characteristics of the de-territorialized refugees. As a place that operates in a different way from Korea, the butcher shop is described as follows:

There was no Muslim that came to the butcher. Most of the customers were local or non-Muslim people coming from outside the area. There were some people coming by occasionally to sell daily installment loans, meat cutters or freezers for the shop. Among the people who came to the butcher, natives, Koreans that is, pretended they did not know Mr. Hassan outside the butcher shop. The threshold of the butcher's is not a mere threshold, but a boundary that divides this world from the other world. (22; emphasis added)

A man of few words who frowns all the time, Hassan does not interact with other Muslims either. The class of native 'Koreans' who come to the Butcher's are 'transparent' people who are not featured in the novel. From the standpoint of the Islamic butcher's realm, the pseudo-family with scars and the pidgin users do not associate with the 'Koreans'. These two groups are isolated from each other by the "boundary that divides this world from the other world" (22). Hence, for the attributes of a refugee novel to become prominent, the story must be narrated according to the grammar of this world. To meet the purpose, unrefined, nonstandardized words are poured out. The drunkard old locksmith always repeats the same words.

"You know who I am?"

"Elephant."

"What kind of elephant?"

"A pink one."

"What is he doing?"

"Passing by." 
"To where?

“..." $(36-37,63,88-89,126-127,180)$

People in "this world" are either refugees who are poor at the Korean language, those who claim they communicate with animals, or those who mumble words that do not make sense. "De-territorialized languages-animal language, repeated words, pidgin, meaningless words, silence, curses, slang, stuttering, and chattering-bring about a peculiar effect of strangeness, humor, wit, and irony" (M. Lee 507). It is not difficult to see here what the novel aims for. Even when the novel separates "this world" from "the other world," it describes or dismantles "this world" in the language of "the other world." As Deleuze and Guattari criticize, "History is always written from a sedentary point of view and in the name of a unitary State apparatus, at least a possible one, even when the topic is nomads. What is lacking is a Nomadology, the opposite of a history" (23). This criticism can be applied to today's multicultural discourse. Although this discourse is sometimes sharp and critical, it is hard to break from the state apparatus the moment it is conceived in the existing normal grammatical system. Considering this, it is somewhat understandable that Islamic Butcher Shop is narrated through images of non-national attributes that come from Turkey, Greece, and the orphanage. It is clear that the novel desires a utopia that Deleuze and Guattari suggest: "doing away with foundations, nullifying endings and beginnings" (25).

Hassan adopted the narrator, but because he is a refugee, he cannot legally file to register him as family. In this "state apparatus," he only has the status of a guardian. Adoption does not mean that the adoptee becomes a family member, and this somehow relates to the narrator's name being unknown. It should be noted here that this novel begins with, "The blood of my stepfather runs in my body" (7), and also ends with, "The blood of my stepfather still runs in my body" (237). Their solidarity is far more accepting and sharing in nomadic terms than any legal devices or bloodline. Let's take an example from Hassan's deathbed at the end of the story:

"Did you hear me? I love you. -.... I LOVE YOU!

I felt the blood of my stepfather in my body. It was hot. I just realized for the first time that all memories are simply and honestly connected. I will transfer the blood of my stepfather to my children someday. The thought had popped into my head when I was in the corner of the hospital room and it embraced me. I decided to adopt this view on that day. (236)

Here we see that the patriarchal system based on bloodline is connected ideologically with the concept of "rhizome" argued by Deleuze and Guattari. The 
context connected not by lineage, but by alliance, is obtained through the "refugee" narrative, which has vacated the origin and center.

A rhizome has no beginning or ending: it is always in the middle, between things, inter-being, intermezzo. The tree is filiation, but the rhizome is alliance, a unique alliance. The tree imposes the verb "to be," but the fabric of the rhizome is the conjunction, "and... and...and..." (25)

In "this world," which is a gathering of refugees connected with each other through scars, they envision a utopia beyond blood relations and the rules and institutions of the nation-state. In this utopia, people inherit the blood of their stepfathers and pass it on to those to come.

However, this novel does not skirt the tough issue of refugees simply by imagining a utopia. They now have to move again. At the maze-like hillside shanty town, the redevelopment boom of capitalism has arrived, and the Islamic Butcher Shop which had been rented, now must be closed. Gentrification is not interested in the immobility of "this world," which represents a poor social minority without geographic mobility. The shop had to be closed anyway, due to Hassan's illness. However, "I" (the narrator), witnessing the sight of the demolition of "this world," feels that his scars are responding to the demolished village. The suffering of refugees in "my" body is reproduced, and the untold suffering of Mr. Hassan as a refugee leaves room for the reader to re-interpret it as the suffering of a good man. The reason is that Hassan's life of silence and endurance was a good life bearing the suffering of the world alone.

However, readers have a premonition that the refugee community, which will soon be demolished, will move somewhere else, and be re-made. Capitalism, which is indifferent to the scars of refugees, and state power, will continue to follow them and urge their movement. The novel prompts us to listen to the language of the refugees and imagine "this world" in which solidarity of suffering is possible. By doing so, Islamic Butcher Shop suggests a refugee worldview that stands up to violence. 


\section{Notes}

1. Born in 1975 in Jeongeup, Jeollabuk-do Province, located in southwest Korea, Son Honggyu started his literary career with his 2001 Rookie Award from Writer's World (a literary quarterly published in Seoul). His works include short stories collected in Myth of Humans (2005), The Age of Ghost (2006), Thus Spoke Bongseop (2008), and Islamic Butcher Shop (2010). He received the 6th Baek Shin-ae Literary Award with his book of collected stories Tom Slept with Tom (2012). In his works that focus on the miserable conditions of immigrants, Son Hong-gyu levels bitter satire at the anti-humanitarian attitude of Koreans toward people coming from outside the country. Islamic Butcher Shop can be considered one of his representative works.

2. A well-known case can be found in Choong-sin Kim, a military officer who came over to Korea to fight in the Japanese invasions of Korea (1592-1598) and took refuge in the Joseon Dynasty (see Fujiwara 59-112).

3. Koo Kim, Baegbeom Ilji, Beomwoosa, 2000.

4. In general, the consistent policy of South Korea for people who escaped from North Korea is to embrace them as compatriots to provide relief, based on the expectation of unification in the future, which is bound to distinguish them from being foreign "refugees."

5. The fact that a person with nationality cannot be in the land that has granted them nationality, but has to stay outside, means that there exists a fear of persecution within this land, and it might be due to conflict, civil war, or some devastating incident like a riot. Therefore, the person cannot be protected by the country of their nationality, and even if he can be protected, the person refuses to receive such protection because of fear (see I. Park 93). 


\section{Works Cited}

Deleuze, Gilles, and Felix Guattari. A Thousand Plateaus: Capitalism and Schizophrenia.

Translation and foreword by Brian Massumi, U of Minnesota P, 1987.

Fujiwara, Takao. "A Study on the Historical Materials and Research Data of Sayaka." Journal of Joseon History, vol. 25, 2016, pp. 59-112.

Kim, Jooyoung. "New Horizon for Interpretation of Multicultural Literature in Korea: Centered on Multicultural Imagination Shown in Son Hong-gyu's Novel and Ha Jongoh's Poetic Literature." Universitas-Monthly Review of Philosophy and Culture, May 2015, pp. 37-56.

Kim, Koo. Baegbeom Ilji. Beomwoosa, 2000.

Kim, Moon-sik. "Choson Intellectual's Understanding of Holland in the 18th Century." The Historical Journal, vol. 39, 2007, pp. 27-46.

Lee, Byung-ha. "The Politicization of Refugee Issues in South Korea", Culture and Politics, vol. 5, no. 4, 2018, pp. 38-40.

Lee, Mi-rim. "A Study on Multicultural Thinking and Gaze of Others in a Novel by Son Hong-Gyu - With a focus on The Islamic Butcher Shop (Moonji Publishing, 2010)."

Hanminjog-Eomunhag, vol. 64, 2013, p. 491-516.

Park, Dong-chan. "The Statistics of the Korean War." Military Compilation Institute at the Ministry of National Defense, 30 June 2014.

Park, In-heon. "A Study on the Refugee Act of Korea from the Viewpoint of Protection of Human Rights." Journal of Human Rights \& Law-related Education, vol. 9, no. 2, 2016, p. 93.

Song, Jong-ho, "For Multiculturalism in Korea: A Reconsideration of the Idea of Protecting the Refugees." Ethnic Studies, vol. 23, 2005, p. 87.

Son, Hong-gyu, 이슬람정 육점 [Islamic Butcher Shop]. Moonji Pub., 2010. 